\title{
DE COMO O ENFERMEIRO ESTÁ INSERIDO NO SEU "ESPAÇO”
}

*Emília Luigia Saporiti Angerami

** Maria Cecília Puntel de Almeida

$\operatorname{ReBEn} / 01$

Angerami E.L.S. e Colaboradora - De Como o Enfermeiro Está Inserido no Seu "Espaço". Rev. Bras. Enf.; RS.36: 123 - 129, 1983.

\section{RESUMO}

Espaço, neste estudo, é entendido como o lugar de inserção ou ação social do enfermeiro e por conseguinte, de sua produção no interior de uma situação sócio-histórica determinada. As questões que se nos colocam são as seguintes: Como os enfermeiros estão inseridos no seu espaço profissional? Como desempenham sua prática? Dentro deste contexto a enfermagem tem buscado seu espaço de atuação e pode-se perceber que seus limites são irregulares e suas fronteiras são invadidas por outros profissionais, assim como também o enfermeiro ultrapassa estes limites.

O espaço do enfermeiro foi analisado na sua totalidade, foi feita uma apresentação da realidade do "espaço" do enfermeiro tal qual ela se mostra, a seguir esta realidade foi julgada e por fim apresenta-se o espaço do enfermeiro numa perspectiva práxica.

\section{INTRODUÇÃO}

Este trabalho nasce da reflexão sobre o tema da percepção do espaço do enfermeiro na sua

prática.

A palavra "espaço" nesta última década tem sido utilizada com freqüência na vida cotidiana e não raras vezes criado sérios atritos quando os "espaços são invadidos".

O tema do espaço, de sua percepção, pertence às ciências humanas e segundo Bettanini ${ }^{7}$ "não como reflexão unitária, conseqüencia de uma preocupação com o espaço sempre relativa ao objeto de análise próprio de cada disciplina”, para ele “do conceito de espaço as ciências humanas derivam uma pluralidade de espaços, de noções que utilizam as orientações da abstração científica, mas relacionando-as sempre ao enfoque psicológico, sociológico, etnológico, geográfico próprio ao objeto de suas análises" e complementa "a bibliografia mais exaustiva sobre o tema da percep̧̧ão do espaço nasce dentro do território geográfico e se expande para as ciências humanas".

O que é então, o espaço? Bettanini7 responde com duas reflexões:

- "o espaço é um lugar comum é o lugar comum (porque dele se fala e nele se vive);

- "mas não se trata certamente de uma espécie de cena vazia onde poderia chegar qualquer um. Ao contrário, o espaço é ... aquilo que nele acontece. E o que significa "acontecer"? Significa "ter lugar" justamente: quero dizer que nossa linguagem está "repleta de espaços que não teriamos condições de falar nem de escrever sem múltiplas referências a alguma forma de espacialidade" (Guivaud17). Dentro do espaço, portanto, se desenvolve, ou acontece algo, acontecem eventos. Eventos que pressupõem a intervenção de indivíduos e de objetos. Pode-se portanto partir de uma noção de espaço definida "pelo Fazer que nele se desenvolve”. (Grupo 10716). Há um pressuposto recíproco entre o espaço e o Fazer:

- não pode haver um fazer sem um espaço que o contenha;

- não pode haver percepção de espaço sem nele se realizar, ver ou imaginar um fazer. Realizar ou ver um fazer, implica a existência deste fazer e o pressuposto está satisfeito. Imaginar um fazer implica a não existência do fazer, mas seu ser latente, a pressuposição está mais uma vez satisfeita (grupo 10716).

Espaço, neste estudo, será entendido como o lugar de inserção ou ação social do enfermeiro e por conseguinte de sua produção no interior de uma situação sócio-histórica determinada. Com esta categoria se quer dizer que o enfermeiro é também um agente social, que ele faz enfermagem em algum

* Professor Adjunto da Escola de Enfermagem de Ribeirão Preto da Universidade de São Paulo.

** Professor Assistente da Escola de Enfermagem de Ribeirão Preto da Universidade de São Paulo. 
Angeramı E.L.S. e Colaboradora - De Como o Enfermeiro Está Inserido no Seu "Espaço". Rev. Bras. Enf.; RS.36: 123 - 129, 1983.

lugar social, que faz uso dos meios que a sociedade lhe oferece e que produz conhecimentos e significações que são dotados de existência e destinação sociais determinados. Tal é na verdade a situação de todo o intelectual no campo social.

Delimitado o significado de "espaço", pretendemos neste trabalho analisar o "espaço", do enfermeiro na sua totalidade. Faremos uma apresentação da realidade do "espaço" do enfermeiro tal qual ele se mostra. A seguir esta realidade será julgada e por fim faremos a apresentação do espaço do enfermeiro numa perspectiva práxica.

\section{DOS LIMITES E DA OCUPAÇÃO DO ESPAÇO}

A enfermagem como profissão e o enfermeiro como profissional, através dos tempos, tem procurado social e historicamente definir seu espaço de inserção, entretanto temos observado limites irregulares onde outros profissionais assumem o que é do enfermeiro, sem entretanto o inverso deixar de ser verdadeiro. Haja visto o que dizem Barbato e col. 5 "em certas situações as enfermeiras tornam-se capazes de desempenhar algumas funçōes não propriamente suas e sim dos médicos e que posteriormente por negligência de ambos, passam a ser rotinas das enfermeiras". Oliveira 20 em estudo das funções de enfermagem apresenta: "Funçōes médicas delegadas: atividades de tal natureza, parece-nos que não constituem campo especifico da enfermagem, pois implicam geralmente na execução de tarefas médicas simples, já rotinizadas ou sistematizadas". Santos ${ }^{25}$ refere que "pelo princípio de delegação de funçōes, as enfermeiras vêm assumindo algumas responsabilidades médicas, e com isto, participando de maneira crescente e ativa nos programas de melhoria do nivel de saúde das coletividades". Gonçalves ${ }^{15}$ numa fase de seu estudo diz:

- "os inumeros trabalhos auxiliares que se vão incorporando à produção dos serviços médicos correspondem, de um lado, a ampliação do campo de aplicação da medicina, mas também correspondem, de outro lado, ao processo contínuo de divisão das funçöes do trabalho, que não pode ser tomado apenas como contrapartida técnica daquela ampliação, mas exprime o seu signifïcado mais profundo na reprodução da divisão trabalho intelectual/trabalho manual, no seio do trabalho médico. Todo o trabalho direto de cuidado ao doente comporta inúmeras funções "manuais", e são essas as primeiras a se separarem subordinadamente no trabalho médico, constituindo a enfermagem. A própria enfermagem é atingida posteriormente para reinteração da mesma divisão, sendo sufïciente para compreender seu sentido a consideração da apropriação das tarefas de supervisäo e controle pelo profissional com qualifïcação formal superior, o enfermeiro".

Talvez pela proximidade entre o trabalho do médico e do enfermeiro este tem sido o "espaço" mais estudado, entretanto, pode-se observar na prática que entre o enfermeiro e outros profissionais, além do médico, há também indefinições que aparecem no cotidiano. Pluckham ${ }^{23}$ também faz referência a isto dizendo: "as discíplinas para-médicas também têm liberdade para crescer, criar e propiciar o melhor cuidado à saúde possivel, dentro de suas capacidades, os médicos devem não somente abdicar de algumas de suas prerrogativas territoriais, mas também de seu paternalismo".

Por sua vez, o espaço profissional do enfermeiro, que deveria ser ocupado por este, desde o momento que a enfermagem passou a ser tida como profissão, é preenchido efetivamente por elementos com três níveis de formação e que percebem salários diferentes, o que nos leva a esperar que desempenhem papéis diferentes. Entretanto na observação prática, isto não ocorre, a realidade mostra limites frouxos onde o atendente, o auxiliar, o técnico e o enfermeiro executam as mesmas funções indiscriminadamente. Ferreira-Santos e Minzoni 14 atestam "verificamos pois que os auxiliares de enfermagem exercem funçōes que deveriam ser executadas por enfermeiras e estão desperdiçando seu preparo em funçöes de atendentes". Em estudo posterior, Ferreira-Santos ${ }^{13}$ diz: "foram encontradas muitas inconsistências mostrando estar o papel do enfermeiro mal integrado no hospital como sistema social e na sociedade global" $\mathrm{e}$ mais adiante continua "estão presentes no sistema, outros elementos com possibilidades de apropriação de tarefas que deveriam estar afetas às enfermeiras".

Nestas duas últimas décadas, vários estudos tem sido realizados procurando identificar através de estudo de funçōes, o que o enfermeiro faz. Como já dissemos espaço é um lugar social onde acontece algo e pressupōe um fazer . As pesquisas de Alvim e coll $^{1}$, Ferreira-Santos e Minzoni ${ }^{14}$, Ferreira-Santos ${ }^{12}$, Trevizan ${ }^{28}$, Batista ${ }^{4}$, Becker e coll ${ }^{6}$, Fávero e col $^{11}$, Botura e col$^{8}$, Balielo ${ }^{3}$, Burlamaque 9 , mostram o que faz o enfermeiro no espaço que lhe é designado. A enfermagem tem um espaço físico temporal perfeitamente delimitado pela estrutura administrativa, e que, por enquanto não tem sido reivindicado por nenhum outro profissional que é de estar no hospital durante 24 horas, num rodízio de plantões. Pois a assistência de enfermagem é mantida pelas instituições, durante 24 horas ininterruptamente. Enquanto os outros profissionais desempenham suas funções junto ao paciente e retornam apenas quando solicitados ou em períodos marcados; atualmente, com os melhores meios de comunicação, é freqüente uma central de informaçōes acionar toda uma equipe assim que se fizer necessário. Esta situação dá à equipe de enfermagem o "privilégio" de "estar 
Angerami E.L.S. e Colaboradora - De Como o Enfermeiro Está Inserido no Seu "Espaço". Rev. Bras. Enf.; RS.36: 123 - 129, 1983.

24 horas ao lado do paciente". Os autores anteriormente citados*, que tratam das funções de enfermagem, utilizando o método de observação sistematizada delinearam como os membros da equipe de enfermagem utilizam estas 24 horas. As conclusōes são semelhantes, variando apenas em porcentagem de tempo. Assim pode-se verificar que quanto mais elevada a formação profissional maior é a distância deste profissional do paciente, desenvolvendo funções denominadas administrativas. Os elementos de menor preparo profissional, ou seja atendentes e auxiliares, são os que realmente permanecem 24 horas ao lado do paciente. Autores como Ferreira-Santos ${ }^{12}$, Batista ${ }^{4}$ e Botura e col. ${ }^{8}$ procuraram inquerir os enfermeiros sobre a satisfação na realização de suas atividades e apenas no trabalho de Batista ${ }^{4}$, os enfermeiros mostraram-se satisfeitos com a situação, os demais revelam interesse em permanecer e atuar mais junto ao paciente e alegam que este distanciamento não permite conhecer o paciente e sua família. Angerami e $\mathrm{col}^{2}$ num estudo sobre comunicação entre médicos e enfermeiros, aqueles referiram a importância da anotação de enfermagem, pois é ela que permanece 24 horas ao lado do paciente. Aliás este aspecto é freqüentemente citado em estudos. Assim se referiram Carvalho e Castro ${ }^{10}$ sobre este fato: "neste ponto é preciso não esquecer que já foi enfatizado à sociedade e a té cantado em prosa e verso, o fato de ser a enfermeira o unico profissional da equipe de saude a permanecer 24 horas do dia e durante os sete dias da semana. No entanto, talvez valesse a pena refletir mais profundamente sobre o sentido dessa permanência. Será ela percebida pelas pessoas internadas e seus acompanhantes, pelos profissionais de plantão e pelo pessoal de enfermagem como segurança e apoio, ou como uma presença controladora? Aqui todas as conjeturas e suposições são cabiveis". Ideologicamente esta permariência contínua favorece o enfermeiro maior entrosamento com o cliente, profundo conhecimento de suas necessidades bio-psico-sociais, percepção imediata de alteraçōes físicas e emocionais e seu pronto atendimento, ajuda e orienta a assistência de enfermagem. Esta ideologia está velando a verdadeira realidade; ideologicamente o "espaço" do enfermeiro está "claro" entretanto como se verificar os estudos revelaram que o enfermeiro tem se desgastado em executar rotinas de trabalho traçadas, cumprindo ordens médicas, executando tarefas administrativas e esta situação tem aberto flancos para outros profissionais exercerem atividades assistenciais que são ou foram da competência do enfermeiro, deixando ao enfermeiro a execução de tarefas de menor importância quase ao nível de mordomia. Ribeiro 24 no seu "Diseurso de posse" na presidência da ABEn em 1980, disse: "Não há vazios que não sejam ocupados e, se os espaços físicos, sociais, culturais ou institucionais que nos cabem, deixarem de ser preocupação nossa, de cada um e de todo o grupo profissional, poderão eles se transformarem em problemas maiores para a classe, pois outros tentarão e poderão ocupá-los".

\section{DA COMPREENSÃO DO ESPAÇO}

Portanto, o "espaço" ocupado pelo enfermeiro não é um espaço claro, definido e delimitado. Mesmo a divisão técnica do trabalho de enfermagem que elege a equipe, atribuindo funçōes diferentes e de níveis de complexidade distintos, não é capaz de delimitar um espaço específico para o enfermeiro. Que mecanismos podem explicar estas indefiniçōes? As causas parecem ser mais de ordem social do que técnicas e podem ser procuradas, dentro da equipe de saúde, na estrutura econômico-social do país, no sistema de saúde e na competência do enfermeiro, e é sobre elas que passaremos a escrever.

- A equipe de saúde - tem conformação variada dependendo de seu local de atuação, entretanto o médico e a equipe de enfermagem são os elementos constantes e portanto, freqüentemente criam um "espaço conflitivo" com situaçōes ora delimitadoras, ora dependentes. Delimitadoras quando a complexidade hierárquica e as relaçōes de poder impedem a liberdade de ação e limitam o processo de decisão. Dependentes quando as relaçōes entre os agentes impedem a autonomia entre eles. Nogueira ${ }^{18}$ em seu estudo mostra que o trabalho dos serviços de saúde é um trabalho associado, destacando-se o médico como produtor principal. A ele cabe tarefas que requerem maiores conhecimentos técnicos, detém portanto, a hegemoria do controle técnico e às vezes administrativo do processo de trabalho. $\mathrm{O}$ médico encontra-se posicionado no vértice de uma pirâmide de autoridade técnica em que a base é constituída pelo exército dos atendentes de enfermagem, havendo de permeio um número menor de profissionais de nível superior e médio que supervisionam a aplicação das ordens médicas, executando eventualmente eles próprios cuidados de enfermagem. As tarefas mais complexas são reservadas ao profissional de maior capacitação, para evitar a perda de seu tempo em atos que possam ser assumidos pelos trabalhadores menos capacitados e conseqüentemente mais baratos. A decisão e

\footnotetext{
*É preciso considerar nos achados, os diferentes critérios de classificação das funçōes, adotados pelos autores.
} 
Angerami E.L.S. e Colaboradora - De Como o Enfermeiro Está Inserido no Seu "Espaço". Rev. Bras. Enf.; RS.36: 123 - 129, 1983.

as intervenções mais complexas ficam a cargo do médico, ou seja, é ele quem diagnostica e prescreve a terapêutica, sendo portanto o "dono" do paciente e monopolizando o saber não permitindo, muitas vezes, ações e decisões de enfermagem com o seu paciente. Silva ${ }^{26}$ relata que no nível secundário e terciário nas ações de saúde, a autonomia do enfermeiro é menor que no nível primário. Possivelmente é naqueles dois níveis que o "espaço conflitivo" é maior, uma vez que ele está absolutamente preenchido pelo saber médico e permitindo a penetração do enfermeiro até o limite por ele desejado. $\mathrm{O}$ enfermeiro por sua vez também monopoliza o saber de enfermagem, ficando as tarefas consideradas "mais manuais" com as auxiliares e atendentes de enfermagem. As relações de poder, os que se traduzem nas relações de dominação e subordinação são reproduzidas pelos elementos de toda a equipe. A estas duas categorias ocupacionais recai a maior sobrecarga de trabalho, pois elas são obrigadas a cumprir as determinações médicas e dos enfermeiros, obrigando-as a horas extras e plantões dobrados no esforço de ao prolongar a jornada de trabalho, compensar seus diminutos salários. Este esforço provoca o cansaço e o desgaste pessoal passando a ser fator risco para a população assistida. É evidente que esta situação reflete o que está além do interior da instituiçào.

- A estrutura econômico-social do país - onde o desemprego, a violência, as descriminações sociais têm favorecido a seleção de grupos e profissões. Os profissionais são egressos de um sistema educacional elitista. $\mathrm{Na}$ escola, o aluno experimenta mais uma vez a divisão de classe, entre quem pode mais e quem pode menos. Superada a barreira do vestibular, que não o conduz, na maioria das vezes, a optar pela carreira desejada, mas pela possível, inicia-se a luta por um emprego. E nesta busca, as relações interpessoais se aviltam e instala-se uma crise entre o eu pessoal e o eu social, tornando difícil qualquer opção. Em se tratando a enfermagem de uma profissão da área da saúde, o enfermeiro tenta ocupar seu espaço no sistema de saúde. Assim se exprime Oliveira21 "Duplamente discriminada pela sua condição de mulher e de enfermeira, o seu relacionamento com outros profissionais é, não raro, cheio de tensões, exigindo um esforço consciente para que seu trabalho não minimizado ou, até mesmo ofuscado. Conquanto se trate do maior contingente de pessoal do campo da saúde, incluindo-se as categorias auxiliares, é ainda diminuta sua participação de cúpula quando se trata de definir as políticas de saúde. Os Ministérios, tanto da Saúde quanto da Previdência não têm sequer um Departamento ou Coordenação de Enfermagem, com força suficiente para influciar na organização e contribuir para torná-la mais eficiente".

Nas instituições de saúde, sejam hospitalares ou serviços de atenção primária o número de cargos de enfermeiros é pequeno, sendo mais evidente ainda nas instituições particulares. Do pessoal de enfermagem são contratados em proporção maior os atendentes de enfermagem e mesmo assim, em número insuficiente provocando uma sobrecarga de trabalho como já foi dito. Portanto, o espaço a ser ocupado pelo enfermeiro muitas vezes não é ocupado ou é substituído por pessoal não preparado e portanto, mão de obra barata que não encarecerá os custos hospitalares e que fornecerá a não qualidade e quantidade de assistência. "A grande maioria ou a quase totalidade dos hospitais não governamentais não dispõe, ainda de enfermeiras para dar cobertura assistencial direta. (...) Esta é portanto, uma das primeiras características de hospital não governamental, isto é, aparência permanente de profissional não enfermeira. Este problema é considerado por muitas enfermeiras, como insolúvel, pois a primeira preocupação de qualquer empresário, assim considerado também os proprietários ou sócios e o diretor do hospital, é obter o máximo de renda... . Por ser mais onerosa a contratação de enfermeiras, estas são substituídas por auxiliares de enfermagem $e$ até por atendentes, a quem são entregues atribuiçōes e responsabilidades que deveriam caber somente às enfermeiras". (Oguisso e Schimidt ${ }^{19}$ ). Ainda Pincanço e col22 numa avaliação feita no serviço de enfermagem de hospitais, contratados pelo então INPS, na cidade de São Paulo, verificam que "nos hospitais estudados, $66 \%$ do pessoal de enfermagem era representado por atendentes; $28,3 \%$ por auxiliares de enfermagem; $0,8 \%$ por obstetrizes; $0,2 \%$ por técnicos de enfermagem; e apenas $4,7 \%$ por enfermeiras. (...) Desses hospitais, somente metade possue enfermeiras na chefia dos serviços de enfermagem".

As razões dessa situação seriam relativas ao pequeno número de enfermeiros disponível no mercado de trabalho? Talvez o pequeno número possa explicar parcialmente o problema, mas na atualidade já se tem referência da não absorção, pelos serviços de saúde, do contingente de enfermeiros disponíveis ou então subempregos.

- A competência - é o outro fator a ser considerado, quando se trata de ocupação de um espaço. A formação da competência do enfermeiro, inicia-se no ensino formal de enfermagem, que corresponde ao curso de graduação. Esta formação tem sido discutida e questionada, especialmente no que diz respeito a adequação do ensino à realidade, ficando o aparelho formador dividido entre a formação de pessoal para atender as necessidades da população e/ou mercado de trabalho da saúde que é especializado e centrado nos aspectos curativos. Botura e $\mathrm{col}^{8}$ relatam em seu estudo que a maioria dos enfermeiros sente-se apenas parcialmente preparada para assumir as atividades práticas, pois o ensino está desvinculado da prática. A competência se faz quando se domina o objeto de trabalho. Para 
Angerami E.L.S. e Colaboradora - De Como o Enfermeiro Está Inserido no Seu "Espaço". Rev. Bras. Enf.; RS.36: 123 - 129, 1983.

dominá-lo é preciso realizar um trabalho de transformação com este objeto, que consta de um fazer que contem um saber.

Analisando o objeto de trabalho da enfermagem, observa-se a aproximação e afastamento em relação ao objeto de trabalho da medicina. Este movimento de ida e volta é histórico e sofreu e sofre influência de fatores ligados ao próprio conhecimento da enfermagem e a fatores sociais. Isto tem sido uma busca da enfermagem para definí-la como uma prática independente e a conseqüente inserção no seu "espaço". Stevens 27 diz que o desenvolvimento da enfermagem como uma prática independente tem ocorrido de modo a resolver o lugar da enfermagem em relação à medicina. As soluções propostas tem explorado os seguintes caminhos alternativos:

1. A enfermagem tem os mesmos pacientes e os mesmos objetivos da medicina.

2. A enfermagem tem os mesmos pacientes, mas objetivos diferentes da medicina.

3. A enfermagem tem diferentes pacientes, mas os mesmos objetivos da medicina.

4. A.enfermagem tem diferentes pacientes e diferentes objetivos da medicina.

Pessoalmente, acreditamos que o item 2 encerra a proposição da enfermagem, mas a realidade prática não tem sido esta. Mesmo, desenvolvendo-se um corpo de conhecimentos que possibilita uma competência para dominar o objeto de trabalho, a nosso ver, a enfermagem encontra-se no estágio primeiro, que é o de ter os mesmos pacientes e objetivos da medicina.

\section{CONCLUSÃO}

Partindo do conceito de "espaço", procuramos olhar para o "espaço do enfermeiro" e analisar sua inserção. $\mathrm{O}$ discurso sobre a enfermagem e sobre o enfermeiro, tem lançado sobre a profissão muitas das culpas de seus sucessos e insucessos. A análise do espaço do enfermeiro na sua totalidade mostra que:

a enfermagem e o enfermeiro como fenômenos históricos, estão socialmente situados e estão sujeitos a transformações em sua praxis, transformações estas, que estão ligadas a mudanças que ocorrem na estrutura social.

Diante desta realidade é imprescindível que os profissionais de enfermagem tomem uma posição e façam uma opção.

A praxis é uma atividade teórico-prática; ou seja, tem um lado abstrato-teórico e um lado propriamente prático, com a particularidade que só artificialmente, por um processo de abstração, podemos isolar um do outro.

A prática requer um constante vai e vem do ideal ao real e as modificações do ideal face às exigências do real.

Se a praxis é ação do homem sobre a matéria para apresentar uma nova realidade, dependendo do grau de penetração da consciência do sujeito no processo prático e da sua criação, teremos níveis diferentes de praxis. Os quais podem ser expressos como: praxis criadora, reinterativa ou imitativa, burocratizada (Vasquez ${ }^{29}$ ).

É importante que os profissionais de enfermagem engajados e preocupados em assumir o seu lugar ou "espaço" que lhe pertence, assumam uma postura crítica e questionando constantemente sua praxis e verifiquem se estão inseridos:

- na praxis criadora a qual permite enfrentar novas situações criando constantemente novas soluções. A praxis criadora é revolucionária, própria de uma consciência inquieta, aberta e receptiva à reflexões e experimentações. Não se encastela em si mesmo, após haver elaborado o produto ideal, mas sim, o vai transformando de acordo com as exigências externas com os meios e instrumentos que dispõe.

- na praxis reinterativa ou imitativa - onde o ideal permanece imutável, pois já se sabe de antemão o que se deve fazer e como fazer. A lei que rege a ação já é conhecida e portanto, basta repetí-la quanto se desejar e obteremos quantos produtos análogos desejarmos. Logo percebe-se que a praxis imitativa tem por base uma praxis criadora já existente, não produz nada de novo, ela apenas tem com lado positivo o fato de ampliar o já criado.

- na praxis burocratizada - nesta praxis, a forma extraída de um processo anterior se aplica a um novo processo, e a lei anteriormente estabelecida se repete até o infinito, mesmo estando à margem do próprio processo prático. Vasquez ${ }^{29}$ diz: "A praxis se burocratiza onde quer que o formalismo ou formulismo dominem, ou mais exatamente, quando o formal se converte em seu próprio conteúdo".

Portanto, qual o espaço que queremos ocupar na assistência à saúde do indivíduo? Queremos um espaço onde possamos dominar o nosso objeto de trabalho, que é o cuidado de enfermagem. Somente dominando-o, ou seja, trabalhando com ele, através dos instrumentos de trabalho da enfer- 
Angerami E.L.S. e Colaboradora - De Como o Enfermeiro Está Inserido no Seu "Espaço". Rev. Bras. Enf.; RS.36: 123 - 129, 1983.

magem, que é o seu saber aliado a um instrumental técnico, podemos atender à finalidade deste trabalho que é prestar assistência de enfermagem aos indivíduos. Como esta prática é social, não perseguimos um espaço com seus limites normatizados, fechados, não um espaço estático, mas sim, uma prática transformadora que acompanhe as mudanças históricas e que permita o desempenho da enfermagem.

Como as práticas se transformam, a todo instante, é preciso trazê-las para o debate e isto cabe a seus agentes que de dentro de seus espaços devem ter uma consciência reflexiva e crítica do seu trabalho, sem perder o ponto de vista de análise das relações sociais.

\section{SUMMARY}

In this study, space is understood to mean the place of insertion or of social action of the nurse, and consequently of the nurse's production in a determined socio-historical situation. We ask the following questions: How are nurses inserted in their professional space? How do they practice their profession? The nursing profession has been looking for its performing space within this context, and it can be seen that its limits are irregular and its frontiers are invaded by other professionals, in the same manner as nurses also go beyond these limits.

The reality of the nurse's "space" as it shows itself has been presented and judged, and a presentation is give of what the nurse's space in a praxis perspective.

\section{REFERÊNCIAS BIBLIOGRÁFICAS}

1. ALVIM, E. F.; BORGES, M. V.; BARROS, T. A. - Pesquisa Operacional das atividades de enfermagem na Fundação S. E. S. P. Rev. Bras. Enf., 19 (4): 236-302, 1966.

2. ANGERAMI, E. L. S.; MENDES, I. A. C.; TAKAKURA, M. S. - A composição das anotaçōes de enfermagem sob o ponto de vista da equipe médica. Rev. Paul. Enf., 2 (1): 27-31, jan/fev., 1982.

3. BALIELO, V. - Análise das atividades do pessoal de enfermagem de um hospital-escola. Porto Alegre, UFRGS/Escola de Enfermagem, 1981. Dissertação (Mestrado), Escola de Enfermagem da UFRGS, $107 \mathrm{p}$.

4. BAPTISTA, W. A. - Contribuição ao estudo da assistência de Enfermagem: análise de alguns fatores relacionados à administração em enfermagem que podem interferir na assistência ao paciente. Ribeirão Preto, USP/Escola de Enfermagem, 1979. Dissertação (Mestrado). Escola de Enfermagem, USP, $183 \mathrm{p}$.

5. BARBATO, M. e col. - Delimitação de funções entre médicos e enfermeiros. Rev. Bras. Enf., 15(3): 185-198, jun., 1962.

6. BECKER, R. S. e col. - Pesquisa Operacional sobre as atividades de enfermagem no conjunto sanatorial Raphael de Paula Souza. Rev. Bras. Enf., 24(1-2): 56-63, jan/mar., 1971.

7. BETTANINI, T. - Espaço e ciências humanas. Trad. por Liliana L. Fernandes. Rio de Janeiro, Paz e Terra, 1982, $157 \mathrm{p}$.

8. BOTURA, A. L. e col. - Estudo sobre as causas que podem concorrer para o distanciamento do enfermeiro da assistência direta ao paciente. In: Congresso Brasileiro de Enfermagem Brasileira, 32, jun. 1-7, 1980. Brasília, 1980. (Mimeografado).

9. BURLAMAQUE, C. S. - Estudo do desempenho do enfermeiro de um hospital de ensino em nível de unidade de internação. Porto Alegre, UFRGS/Escola de Enfermagem; 1981. Dissertação (Mestrado), Escola de Enfermagem da UFRGS, 91 p.

10. CARVALHO, V.; CASTRO, I. B. - Reflexões sobre a prática da enfermagem. IN: CONGRESSO BRASILEIRO DE ENFERMAGEM, 31, Fortaleza, ago 5-11, 1979. Anais Brasília, ABEn, 1979, 51-59pp.

11. FÁVERO, N. e col. - Atividades de assistência direta do enfermeiro e respectiva anotação. Enfermagem Atual, 31(14) 14-16, nov/dez, 1980.

12. FERREIRA-SANTOS, C. A. - A enfermagem como profissão: estudo num hospital-escola. São Paulo. Livraria Pioneira E.D.U.S.P., 1973.

13. FERREIRA-SANTOS, C. A. - A enfermeira como categoria ocupacional num moderno hospitalescola brasileiro. Educación Médica Y Salud, 7(1): 16-29, 1973.

14. FERREIRA SANTOS, C. A.; MINZONI, M. A. - Estudo das atividades de enfermagem em quatro unidades de um hospital governamental. Rev. Bras. Enf., 21(5): 396-443, 1968. 
Angerami E.L.S. e Colaboradora - De Como o Enfermeiro Está Inserido no Seu "Espaço". Rev. Bras. Enf.; RS.36: 123 - 129, 1983.

15. GONÇALVES, R. B. M. - Medicina e história: raízes sociais do trabalho médico. São Paulo, USP/F. M., 1979. Dissertação (Mestrado). Faculdade de Medicina da USP, 209 p.

16. GRUPO 107 - Sémiotique de l'espace, Paris, Publication du Groupe 107, 1973, p.29 apud BETTANINI, T. Espaço e ciências humanas. Trad. por Liliana L. Fernandes. Rio de Janeiro, Paz e Terra, 1982, 157 p.

17. GUILVAUD, M.G. Th. Espaces et mathématiques in A.A.V.V. Notes Methodologiques en architecture et urbanisme. 3/4 sémiotiques de l'espace, Paris, Institut de L'Environnement, 1974, p.285. In. BETTANINI; T. - Espaço e ciências humanas. Trad. por Liliana L. Fernandes. Rio de Janeiro, Paz e Terra, 1982, 157 p.

18. NOGUEIKA, R. P. - Capital e trabalho nos serviços de saúde. Rio de Janeiro, 1981 (mimeografado).

19. OGUISSO, T.; SCHMIDT, M. J. - Problemas assistenciais de enfermagem nos hospitais e clínicas particulares. Rev. Bras. Enf., 28(1): 24-34, jan/mar., 1976.

20. OLIVEIRA, M. I. R. - Funções médicas delegadas, p. 34, in: SEMINÁRIO NACIONAL sobre currículo do Curso de Graduação em Enfermagem. São Paulo, nov. 25-30, 1968. São Paulo, USP/Escola de Enfermagem O. P. A. S., 1969.

21. OLIVEIRA, M. I. R. - Relaçōes da enfermagem com as demais carreiras universitárias. In: CONGRESSO BRASILEIRO DE ENFERMAGEM, 29, Camboriú, 1977. Anais, Camboriú, ABEn, 1977 p. 59-63.

22. PICANÇO, I. T. et alii - Uma tentativa de avaliaçào dos serviços de enfermagem de hospitais contratados pelo Instituto Nacional de Previdência Social I. N. P. S. em São Paulo, 1972. Rev. Bras. Enf., 25(4): 193-214, jul. set., 1972.

23. PLUCKHAN, M. L. - Professional Territoriality - A problem affecting the delevery of health care, Nursing Forum, 11(3): 300-311, 1972.

24. RIBEIRO, C. M. - Discurso de posse. In: CONGRESSO BRASILEIRO DE ENFERMAGEM, 32 , Brasília, jun. 1-7, 1980. Anais, Brasîlia, ABEn, 1980, p. 21-23.

25. SANTOS, I. - apud SEMINÁRIO NACIONAL sobre Currículo do Curso de Graduação em Enfermagem, São Paulo, nov. 25-30, 1968. São Paulo, USP/Escola de Enfermagem/O. P. A. S., 1969, p. 31.

26. SILVA, A. X. - Enfermeiro profissional: autônomo ou subsidiário? In: CONGRESSO BRASILEIRO DE ENFERMAGEM, 31, Fortaleza, ago. 5-11, 1979. 'Anais, Brasília, ABEn, 1979, 71-84 pp.

27. STEVENS, B. J. - Nursing theory: analysis, applications, evaluation. Boston, Little-Brown, $1979,280 \mathrm{p}$.

28. TREVIZAN, M. A. - Estudo das atividades dos enfermeiros-chefes de unidades de internação de um hospital-escola. Ribeirão Preto, USP/Escola de Enfermagem, 1978. Dissertação (Mestrado). Escola de Enfermagem da USP, 117 p.

29. VÁSQUEZ, A. S. - Filosofia da praxis. Trad. Luiz Fernando Cardoso, 2a ed., Rio de Janeiro, Paz e Terra, 1977, 454 p.

\section{OS IDOSOS E A REALIDADE DA VELHICE*}

** Daisy Leslie Steagall-Gomes

*** Tereza Cristina Scatena

$\mathrm{ReBEn} / 02$

Gomes D. L. S. e Colaboradora - Os Idosos e a realidade da Velhice ${ }^{*}$ Rev. Bras. Enf.; RS, 36: $129-151,1983$

\section{RESUMO}

Com o objetivo de conhecer o que acontece com as pessoas que envelhecem e o que elas dizem ser o envelhecimento, as autoras realizaram um trabalho de pesquisa através de entrevistas com pessoas idosas, num total de 93. Dessas, 55 eram albergadas em instituições filantrópicas para idosos e

** Professor Assistente da Escola de Enfermagem de Ribeirão Preto da Universidade de São Paulo

*** Auxiliar de Ensino da mesma Unidade (EERP - USP) 